\title{
Investigation on Impact of Heat Input on Microstructural, Mechanical, and Intergranular Corrosion Properties of Gas Tungsten Arc-Welded Ti-Stabilized 439 Ferritic Stainless Steel
}

\author{
Santosh K. Gupta, Awanikumar P. Patil, Ramesh C. Rathod, Vipin Tandon, and Himanshu Vashishtha
}

Submitted: 12 September 2021 / Revised: 22 October 2021 / Accepted: 19 November 2021 / Published online: 23 December 2021

\begin{abstract}
In the present study, gas tungsten arc welding was employed to weld Ti-stabilized 439 ferritic stainless steel using 308L austenitic stainless steel filler electrode with varying heat input, i.e., low heat input (LHI) and high heat input (HHI). The optical microstructure revealed the formation of retained austenite (RA) and ferrite in the weld zone (WZ), whereas the peppery structure consisting of chromium-rich carbides were observed in the heat-affected zone for both the weldments. The volumetric fraction of RA was calculated using X-ray diffraction analysis. The RA's content decreased, whereas grain size in WZ increased with an increase in heat input. The local misorientation and grain boundary distribution in the welded region was investigated by electron backscattered diffraction. The LHI weldment depicted the higher micro-hardness and tensile strength attributed to the higher content of RA as compared to $\mathrm{HHI}$; however, the opposite trend was observed for the intergranular corrosion resistance.
\end{abstract}

Keywords 439 Ferritic stainless steel, electrochemical behavior, gas tungsten arc welding, mechanical properties

\section{Introduction}

In recent years, there has been a significant increase in the demand for ferritic stainless steels (FSSs) attributed to their economic advantage and a good combination of mechanical and corrosion properties as compared to austenitic stainless steels (ASSs) (Ref 1). The FSSs with chromium (11-30\%) and little or no nickel content are used in corrosive environments such as vehicles, pressure vessels, and power generation. (Ref 2). The FSSs also possesses good oxidation resistance at higher temperature, and therefore, these steels are majorly used in automobile exhaust systems (Ref 3 ).

Fusion welding is the most widely adopted technique to join the FSSs at an industrial scale. However, the major problems of FSSs welding are grain coarsening in weld zone (WZ) and heataffected zone (HAZ) as grain refinement restricted due to the absence of phase transformation from liquid to solid (Ref 4)

Santosh K. Gupta, Awanikumar P. Patil, and Ramesh C. Rathod, Department of Metallurgical and Materials Engineering, Visvesvaraya National Institute of Technology, Nagpur 440010, India; Vipin Tandon, Centre of Sustainable Built Environment, Manipal School of Architecture and Planning, Manipal Academy of Higher Education, Manipal 576104, India; and Himanshu Vashishtha, Department of Materials Science and Engineering, Indian Institute of Technology Delhi, New Delhi 110016, India. Contact e-mails: vipintandon3103@gmail.com and vashishtha.himanshu100593@ gmail.com.

and consequently reduced the mechanical strength as well as corrosion resistance. The grain coarsening can be minimized by limiting the supplied heat input during fusion welding (Ref 1). Moreover, the FSSs also suffers from sensitization during the welding resulting in an intergranular corrosion (IGC) (Ref 5). It is reported that the carbide precipitation occurs faster in FSSs due to the lower solubility of carbon compared to ASSs (Ref 6). Therefore, proper control on the addition of carbon content or by adding titanium (Ti) and/or niobium $(\mathrm{Nb})$ as stabilizing elements has proved to be the most viable option to reduce the IGC without compromising its ductility and corrosion resistance of FSSs weldments (Ref 7).

During fusion welding, the selection of the welding process and parameters plays a crucial role in producing the sound joint. There have been various studies performed on the influence of welding processes and parameters on the microstructural, mechanical, and corrosion properties of FSSs. Mohandas et al. (Ref 8) studied the effect of welding processes on 430 FSS and reported that gas tungsten arc welding (GTAW) welds showed higher ductility and strength as compared to shielded metal arc welding (SMAW). The authors attributed this to the formation of equiaxed grains in the fusion zone and the restricted entry of atmospheric gases by protecting the weld pool via shielding gases. Silva et al. (Ref 9) investigated the microstructural characterization of HAZ of 444 FSS by SMAW process. They observed the presence of carbides, nitrides, carbonitrides and some secondary precipitates such as chi and sigma and needle-like laves phase precipitate near the partially melted zone. Alizadeh-Sh et al. (Ref 10) investigated the effect of phase transformation and mechanical properties of similar welded 430 FSS by resistance spot welding. They stated that the grain coarsening and grain refinement in high-, medium-, and low-temperature HAZ depend on the solidification and cooling rate. Lakshminarayanan et al. (Ref 11) examined the 
effect of different welding processes, namely GTAW, SMAW, and gas metal arc welding (GMAW), on the microstructural and mechanical properties of 409M FSS. The authors reported that the lower heat input associated with the GTAW process resulted in a faster cooling rate and enhanced mechanical properties. Kim et al. (Ref 12) investigated the IGC behavior of 409L FSS. The authors reported that these types of steels suffer IGC when used in a temperature range of $400-600^{\circ} \mathrm{C}$ for a long time after exposure to high temperatures such as arc welding. Lakshminarayanan et al. (Ref 13) compared the sensitization kinetics of 409M FSS welded by GTAW, friction stir welding, laser beam welding, and electron beam welding and reported that friction stir welding exhibited lower sensitization attributed to the formation of more refined grains.

In welding of FSSs, the use of filler material with same chemical composition to base metal (BM) results grain coarsening in WZ, and subsequently, results in the reduced mechanical and corrosion properties of the weldments (Ref 14). Therefore, the selection of filler electrodes plays an essential role in imparting better mechanical and corrosion properties in FSSs. Shojaati et al. (Ref 15) investigated the effect of different fillers (austenitic, duplex, and nichrome) on dissimilar welding of 304 ASS and 409 FSS by GTAW technique. The authors reported that the mixed microstructure (ferrite and austenite) was observed in WZ in austenitic and duplex fillers, and some iron-based precipitates was observed in nichrome filler and concluded that the superior mechanical properties were observed in austenitic filler weld joint. Moreover, Lippold and Kotecki (Ref 16) reported that the use of ASS filler electrodes for welding of FSSs result in the formation of mixed microstructure (austenite and ferrite) in WZ, which subsequently improves the mechanical strength and ductility of the weldments.

Few researchers have attempted to investigate the weldability of Ti-stabilized 439 FSS. Lopez et al. (Ref 17) investigated the microstructural and mechanical properties of 439 FSS with different heat inputs by pulse current GTAW technique without filler electrode. Silva et al. (Ref 18) studied the effect of heat input on the microstructural characterization of HAZ of 439 FSS, welded by manual GMAW using 308L-Si filler electrode and observed that carbide and nitride precipitates in HAZ and width of HAZ and grain size increased with increasing heat input. However, the systematic investigation on the weldability of Ti-stabilized 439 FSS is still scanty. Hence, there is a need to understand microstructural evolutions and their subsequent effect on mechanical properties and intergranular corrosion resistance of welded 439 FSS. Therefore, the present study focuses on the impact of heat input on the similar welding of Ti-stabilized 439 FSS by GTAW technique using a 308L filler electrode.

\section{Materials and Method}

The BM, 439 FSS sheets was procured commercially with an initial thickness of $3 \mathrm{~mm}$. The rolled or milled sheets were solution annealed at $850{ }^{\circ} \mathrm{C}$ for $1 \mathrm{~h}$ in the furnace (carbolite gero) followed by water quenching to eliminate the prior thermal effects (Ref 19). The sheets were cut in the dimension of $75 \mathrm{~mm} \times 100 \mathrm{~mm}$ using a wire-cut electro-discharge machine. The oxide layer was cleaned by an acid pickling solution of $100 \mathrm{ml}$ consisting of $15 \mathrm{ml} \mathrm{HNO}_{3}, 5 \mathrm{ml} \mathrm{HF}$ and water.

The chemical composition of BM and filler electrode is given in Table 1. The GTAW technique was employed to perform the butt welding of 439 FSS plates using a 308L filler electrode. The welding was performed with two different heat inputs, i.e., low heat input (LHI) and high heat input (HHI) in a single pass with a root gap of $1.2 \mathrm{~mm}$. The welding parameters are summarized in Table 2. The heat input was then calculated using the welding parameters by Eq 1 (Ref 20):

$\mathrm{HI}=\frac{\eta \mathrm{VI}}{\mathrm{V}}$

where " $\mathrm{v}$ " is the welding speed in $(\mathrm{mm} / \mathrm{s})$, "I" is the welding current in amperes (A), "V" is the arc voltage in volts (V), and $\eta$ is the welding efficiency which is considered as $60 \%$ for GTAW technique (Ref 20).

The edges of the plates were discarded after welding; $10 \mathrm{~mm}$ from both top and bottom side of the weldments to account for the possible non-uniformity during welding. And then, samples for metallography, mechanical and corrosion studies were obtained. The schematic diagram of weld joints and representation of samples are shown in Fig. 1. The samples were then polished by a series of polishing papers $(200,400,800,1200$, 1500,2000 grit size) followed by velvet cloth polishing using $0.75 \mu \mathrm{m}$ alumina slurry. The samples were then cleaned

Table 1 Chemical composition of base metal (439 FSS) and filler metal (308L ASS) in (wt.\%)

\begin{tabular}{lllllllll}
\hline Material and electrode & $\mathbf{C}$ & Mn & Si & S & Ti & Cr & Ni & Fe \\
\hline 439 FSS & 0.024 & 0.29 & 0.35 & 0.05 & 0.25 & 17.35 & 0.18 \\
308L ASS & 0.03 & 1.69 & 0.75 & 0.03 & $\ldots$ & Bal. & 18.31 & 8.28 \\
\hline
\end{tabular}

Table 2 Welding parameters used in the present study

\begin{tabular}{lcccc}
\hline S. No. & Current, A & Voltage, $\mathbf{V}$ & Welding speed, mm/s & Heat input, J/mm \\
\hline 1 & 110 & 11.1 & 2.9 & 252.62 \\
2 & 80 & 10.6 & 1.5 & 339.2 \\
\hline
\end{tabular}



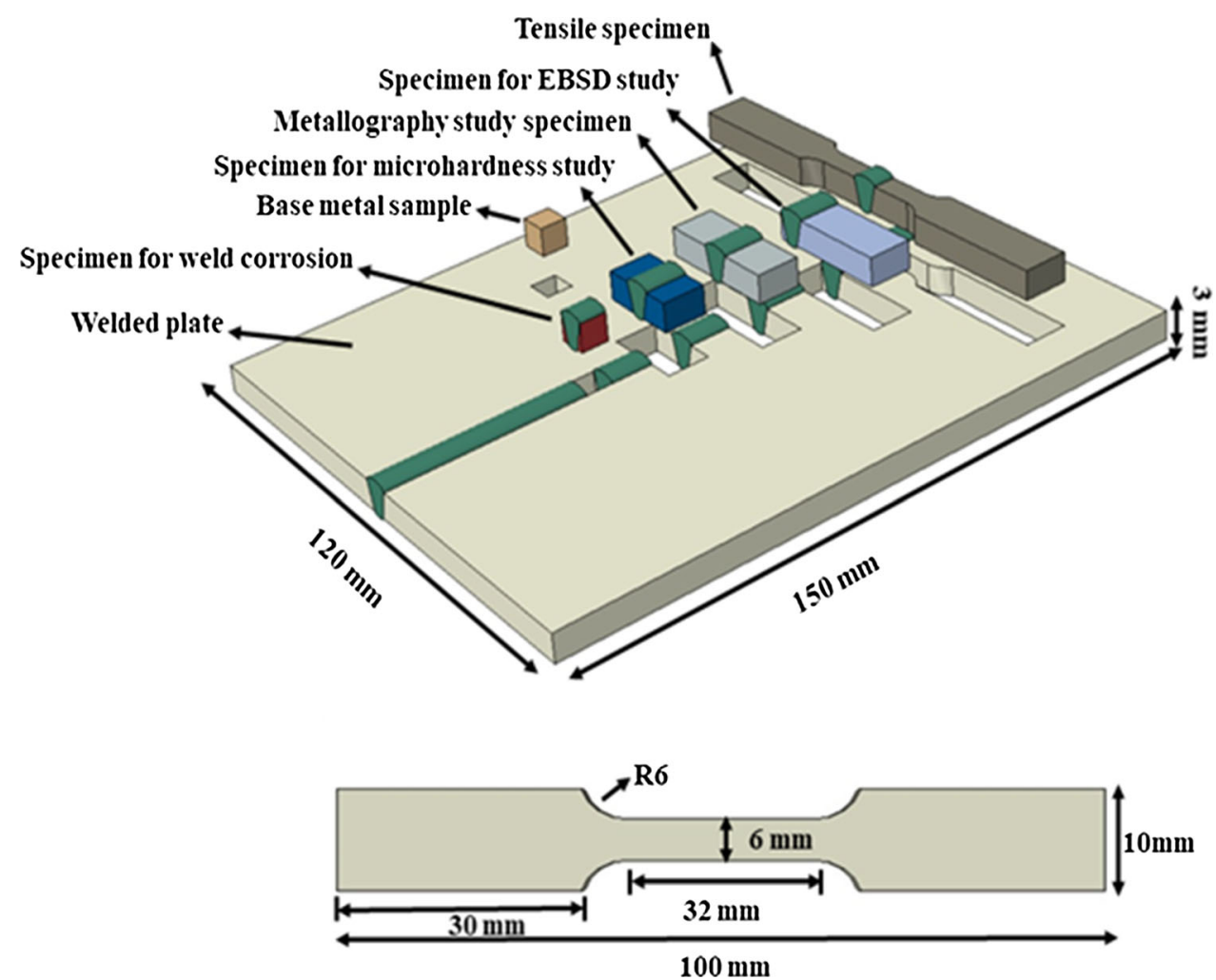

Fig. 1 Schematic representation of specimens obtained from similar welded joints for metallographic, mechanical and corrosion studies

ultrasonically in distilled water for $5 \mathrm{~min}$. An electrochemical etching method was performed in potentiostat (solartron 1285) to reveal the microstructural evolutions in the weldments. A potential of $6 \mathrm{~V}$ is applied for $30 \mathrm{~s}$ in a chemical solution comprising of 90-ml ethanol and 10-ml HCL.

The optical microstructure of WZ, HAZ and BM was observed in optical microscope (OM, Leica DMi8 C), and the presence of different phases in BM and WZ was studied by Xray diffraction (XRD-X'Pert PRO PANanalytical). The scanning electron microscope (SEM - JEOL 6380A, JAPAN) coupled with energy dispersive spectroscopy (EDS) was employed to study the microstructural characteristics and chemical composition of secondary phases in the different zones. The electron backscattered diffraction (EBSD, oxford instruments) was employed to analyze the grain orientation and secondary phase formation. The micro-hardness of the welded samples was obtained using Vickers micro-hardness tester (Simadzu Micro-hardness tester). The $300 \mathrm{~g}$ load was applied for $10 \mathrm{~s}$ to estimate the micro-hardness values of different zones. The tensile test specimens were prepared according to ASTM E8M-04 and tested using an Instron-4467 universal testing machine, followed by fractographic investigation using SEM. The double-loop electrochemical potentiokinetic reactivation (DLEPR) test was performed to examine the susceptibility of IGC. The conventional three-electrode cell, i.e., welded samples as a working electrode, platinum electrode as a counter electrode and saturated calomel electrode (SCE) as a reference electrode, was used for the IGC test. The test was carried out in a solution of $0.5 \mathrm{M} \mathrm{H}_{2} \mathrm{SO}_{4}+0.01 \mathrm{M} \mathrm{NH}_{4} \mathrm{SCN}$ at room temperature $\left(27 \pm 1{ }^{\circ} \mathrm{C}\right)$. The potential range of -500 $\mathrm{mV}_{\mathrm{SCE}}$ to $+300 \mathrm{mV}_{\mathrm{SCE}}$ was used for the forward scan, and the same potential range was used for the reverse scan $(+300$ $\mathrm{mV}_{\mathrm{SCE}}$ to $\left.-500 \mathrm{mV}_{\mathrm{SCE}}\right)$ at a scan rate of $1.67 \mathrm{mV} / \mathrm{s}(\operatorname{Ref} 21)$.

\section{Results and Discussion}

\subsection{Microstructural Evolution}

3.1.1 Optical and Scanning Electron Microscope Analysis. Figure 2(a) depicts an optical micrograph of BM, 439 FSS with a fine-grained and homogeneous structure. The Kaltenhauser (Ref 22) developed an equation to estimate the formation of martensite in FSS, which is known as Kaltenhauser factor or K-factor and is given by:

$$
\begin{aligned}
\mathrm{K} \text { factor }= & \mathrm{Cr}+6 \mathrm{Si}+8 \mathrm{Ti}+4 \mathrm{Mo}+2 \mathrm{Al} \\
& +40(\mathrm{C}+\mathrm{N})-2 \mathrm{Mn}-4 \mathrm{Ni}
\end{aligned}
$$

The $\mathrm{K}$ factor has a critical value of 13 and 17 for low and medium chromium FSS to prevent the formation of martensite in FSS, respectively. In the present study, the medium chromium 439 FSS is used, and the calculated value of Kfactor is 20.55, which is higher than the critical value, and therefore, no martensite is observed in the BM in the optical microstructure. Moreover, the XRD graph (Fig. 2(b)) of BM further confirms the presence of a single-phase body-centered cubic ferritic structure.

In stainless steels (SSs), the chemical composition of BM and filler electrode plays a significant role in determining the solidification mode in the WZ, which can be determined through the WRC 1992 diagram by calculating the ratio of chromium equivalent $\left(\mathrm{Cr}_{\mathrm{eq}}\right)$ to nickel equivalent $\left(\mathrm{Ni}_{\mathrm{eq}}\right)$ ( $\mathrm{Ref}$ 23). The $\mathrm{Cr}_{\text {eq }}$ is calculated using the weight (\%) of ferrite stabilizing element (Eq 3), and $\mathrm{Ni}_{\mathrm{eq}}$ is calculated using the weight (\%) of austenite stabilizing elements (Eq 4). In the present study, the ratio of $\mathrm{Cr}_{\mathrm{eq}} / \mathrm{Ni}_{\mathrm{eq}}$ is found out to be 2.63. 

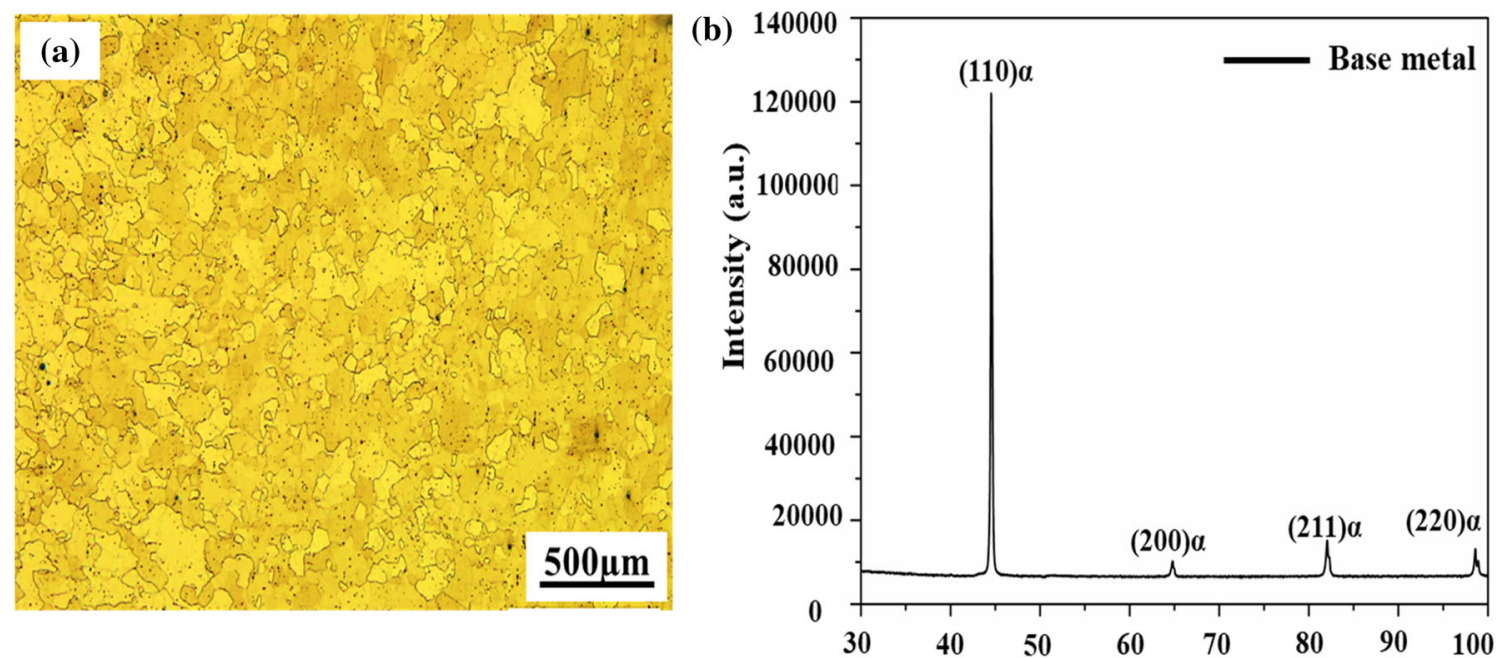

Fig. 2 (a) Optical microstructure, and (b) XRD pattern of 439 FSS base metal

Hence, according to Eq 5 (Ref 24), the solidification mode is ferritic $(\mathrm{F})$.

$\mathrm{Cr}_{\mathrm{eq}}=\mathrm{Cr}+\mathrm{Mo}+0.7 \mathrm{Nb}$

$\mathrm{Ni}_{\mathrm{eq}}=\mathrm{Ni}+35 \mathrm{C}+20 \mathrm{~N}+0.25 \mathrm{Cu}$

Ferrite $(\mathrm{F})$ mode $: \mathrm{L} \rightarrow(\mathrm{L}+\delta) \rightarrow \delta$

$$
\rightarrow(\gamma+\delta) ; \mathrm{Cr}_{\mathrm{eq}} / \mathrm{Ni}_{\mathrm{eq}}>1.95
$$

Figure 3 depicts the microstructural and XRD analysis of WZ for both the weldments. Figure 3(a-b) shows that the microstructures of WZ exhibit the evolution of mixed microstructures during GTAW with varying heat input. In both the weldments, the microstructure illustrates the formation of mixed microstructure, i.e., retained austenite (RA) in the grain boundary and ferrite in the grain matrix. Hence, it can be stated that during the solidification of 439 FSS weldments, the solidification mode is $\mathrm{F}$, and ferrite solidifies upon cooling and transforms to $\delta \rightarrow \gamma+\delta$ in WZ. However, it can be noticed from Fig. 3(b) that the volumetric fraction of RA decreased for the HHI weldment. This may be attributed to the slower cooling rate in the HHI process. The slower cooling rate in the HHI process offers sufficient time for the transformation of the RA phase to the ferrite phase.

The XRD spectrums of WZ are shown in Fig. 3(c). It can be noticed that in WZ of LHI and HHI weldments, the formation of austenite $(\gamma)$ can be observed with respect to the single ferrite phase ( $\alpha$ peaks - Fig. 2(b)). This further confirms the formation of RA in the WZ of weldments. Also, it can be observed that the intensity of peak $\gamma$ decreased for HHI weldment as compared to LHI weldment, indicating that the volumetric fraction of RA decreased with an increase in heat input, as evidenced in the optical microstructures (Fig. 3a-b). The volumetric fraction of RA is estimated according to Eq 6 (Ref 25):

$\mathrm{V}=\frac{\left(\frac{1}{\mathrm{n}}\right) \sum_{\mathrm{i}=1}^{\mathrm{j}}\left(\mathrm{I}_{\alpha}^{\mathrm{j}} / \mathrm{R}_{\alpha}^{\mathrm{j}}\right)}{\left(\frac{1}{\mathrm{n}}\right) \sum_{\mathrm{i}=1}^{\mathrm{j}}\left(\mathrm{I}_{\gamma}^{\mathrm{j}} / \mathrm{R}_{\gamma}^{\mathrm{j}}\right)+\left(\frac{1}{\mathrm{n}}\right) \sum_{\mathrm{i}=1}^{\mathrm{j}}\left(\mathrm{I}_{\alpha}^{\mathrm{j}} / \mathrm{R}_{\alpha}^{\mathrm{j}}\right)}$ where I is integrated intensity, $\mathrm{R}$ is material scattering factor, and $\mathrm{n}$ is the number of peaks of different phases. The $\mathrm{R}$ values are taken from Tandon et al. (Ref 25). The estimated volumetric fraction of RA phase in WZ of LHI and HHI weldments are $33.33 \%$ and $20.42 \%$, respectively. This further confirms that the volumetric fraction of RA decreased substantially on increasing heat input.

Lippold and Kotecki (Ref 16) stated that the initial solidification in FSS welds occurs as primary ferrite; however, the microstructure in WZ can be either fully ferritic, or the mixed microstructure of ferrite and RA and RA is located at the ferrite grain boundaries. The authors (Ref 16) reported the three different type of solidification mode in FSS welds.

$\mathrm{L} \rightarrow \mathrm{L}+\delta \rightarrow \delta$

$\mathrm{L} \rightarrow \mathrm{L}+\delta \rightarrow \delta \rightarrow \delta+\gamma \rightarrow \delta+\alpha$

$\mathrm{L} \rightarrow \mathrm{L}+\delta \rightarrow \mathrm{L}+\delta+\gamma \rightarrow \delta+\gamma \rightarrow \delta+\alpha$

The authors (Ref 16) stated that the solidification mode would occur via Eq 7 if the ferrite promoting elements are dominant than that of the austenite promoting elements and austenite formation is suppressed entirely. However, when the austenite-promoting elements are present, the evolution of microstructure is a mixed-mode (ferrite and RA), and the solidification will occur via Eq 8 or 9. This solidification path promotes the nucleation of austenite at ferrite grain boundary at elevated temperature, which restricts the formation of a single ferrite phase. However, the authors (Ref 16) further stated that the solidification mode would occur via Eq 9 for high carbon FSS (the carbon content in more than $0.15 \%$ ) or the content of austenite-promoting elements are present in high quantity. Therefore, in our present study, the solidification may have occurred via Eq 8, as the BM and filler electrode used in the present study has low carbon content and the content of austenite promoting elements ( $\mathrm{Ni}$ and $\mathrm{Mn}$ ) is not very high. Hence, it can be stated that during the solidification of 439 FSS weldments, the ferrite solidifies upon cooling and transforms to $\delta \rightarrow \gamma+\delta$ in WZ. Moreover, the face-centered cubic (FCC) 

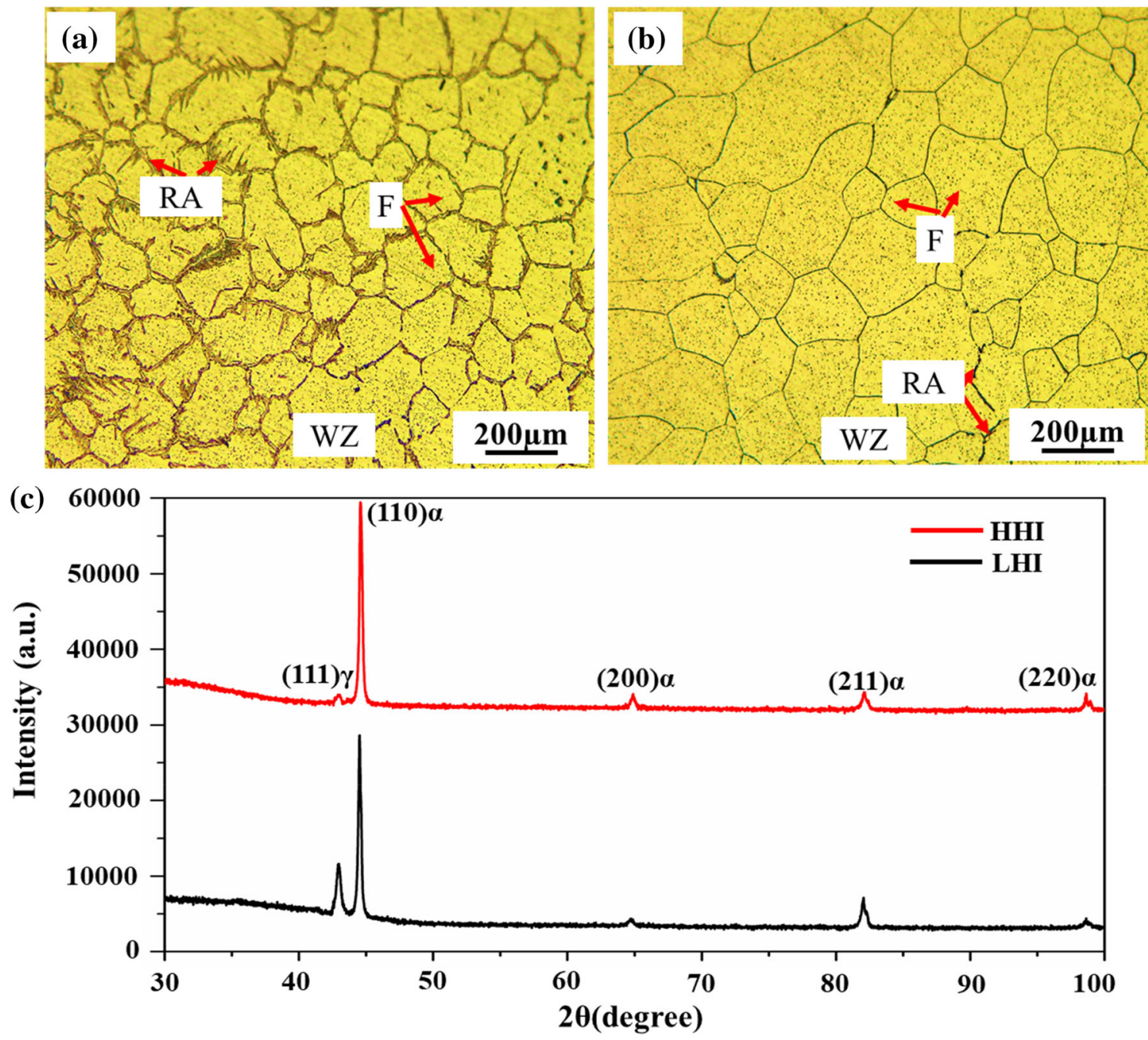

Fig. 3 Optical microstructures of WZ of (a) LHI, (b) HHI weldments (c) XRD pattern

structure of $308 \mathrm{~L}$ filler material will promote the mixed-mode microstructure.

Figure 4(a, b) shows the SEM micrographs of WZs having precipitates coupled with EDX spectra, and the variation in the chemical composition of different elements in the grain area and grain boundary regime is shown in Fig. 4(c, d). It can be observed from Fig. 4(c, d) that the grain boundary has higher $\mathrm{Ni}$ and $\mathrm{Mn}$ content and lower $\mathrm{Cr}$ content, whereas inside the grain, vice versa followed. It is well-defined that $\mathrm{Ni}$ and $\mathrm{Mn}$ are austenite promoting elements, and $\mathrm{Cr}$ is ferrite promoting elements (Ref 16). This further confirms the formation of mixed microstructure, i.e., RA at the grain boundary and ferritic structure within the grain boundaries in WZ of both the weldments, and the results are consistent with the XRD analysis (Fig. 3c). Similar results are obtained by the other researchers $(\operatorname{Ref} 8,26)$.

The optical microstructures of the HAZ region for both the weldments are shown in Fig. 5(a-d). The HAZ region is divided into two parts, namely (i) coarse-grain heat-affected zone (CGHAZ) and (ii) fine-grain heat-affected zone (FGHAZ) for both the weldments. The area near the fusion boundary possesses the coarse grains attributed to elevated temperature and slower cooling rate and is termed as CGHAZ. The area next to the CGHAZ is named FGHAZ. The temperature during welding in FGHAZ is comparatively low and has a faster cooling rate compared to the CGHAZ area, resulting in finer grains (Ref 27). Also, some precipitates can be observed inside the grains, called "peppery structures" (Ref 28). Figure 5(a-d) shows that the precipitates formed are far from the grain boundary, and the area near to the grain boundaries are free from carbides in all the HAZ of weldments and is called a precipitate free zone (PFZ) (Ref 10). The peppery structure represents the carbides that may have formed during cooling due to the lower solubility of carbon in the ferrite phase (Ref 6).

The measured grain size of WZ and HAZ (average of 10 readings are taken) and the width of the different zone in HAZ are shown in Fig. 5(e, f). Figure 5(e) shows that the LHI weldment exhibits a smaller grain size in WZ and HAZ as compared to HHI weldment. The grain size in WZ during welding of FSS is greatly affected by the formation of austenite at elevated temperatures during solidification. It is reported that once the austenite forms along the grain boundaries at elevated temperatures, it restricts the grain growth of the ferrite (Ref 29). In the present study, it is observed that the WZ of LHI weldment exhibited a higher volumetric fraction of RA as compared to $\mathrm{WZ}$ of $\mathrm{HHI}$ weldment, hence, resulting in smaller 
grain size. Moreover, a significant difference in the width in different zones of HAZ is shown in Fig. 5(f). It can be seen that the width of HAZ (combined width of CGHAZ and FGHAZ) increased with an increase in heat input. This can be ascribed to the slower cooling rate for the HHI weldment, which resulted in the higher width of HAZ (Ref 30$)$.
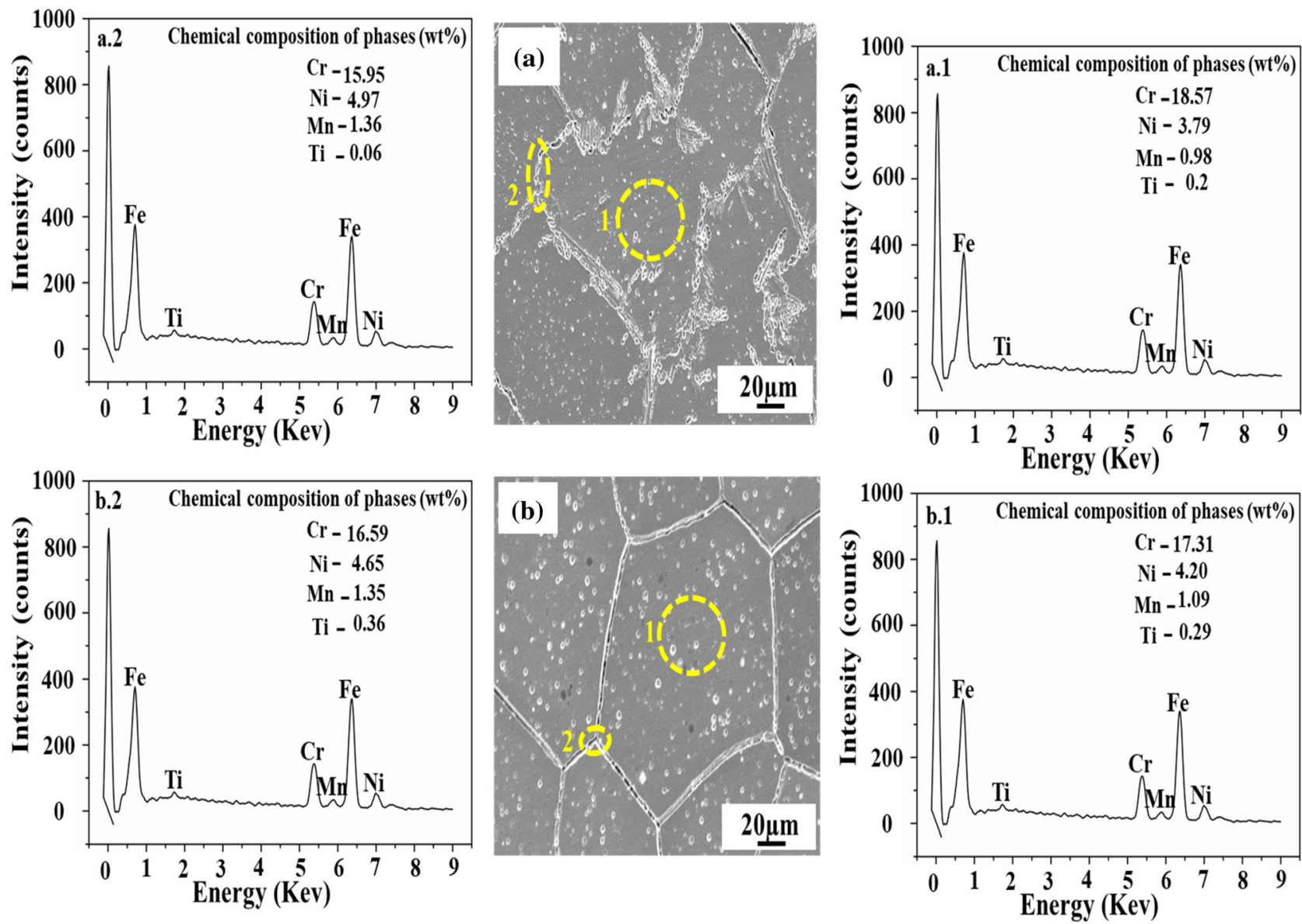

(c)

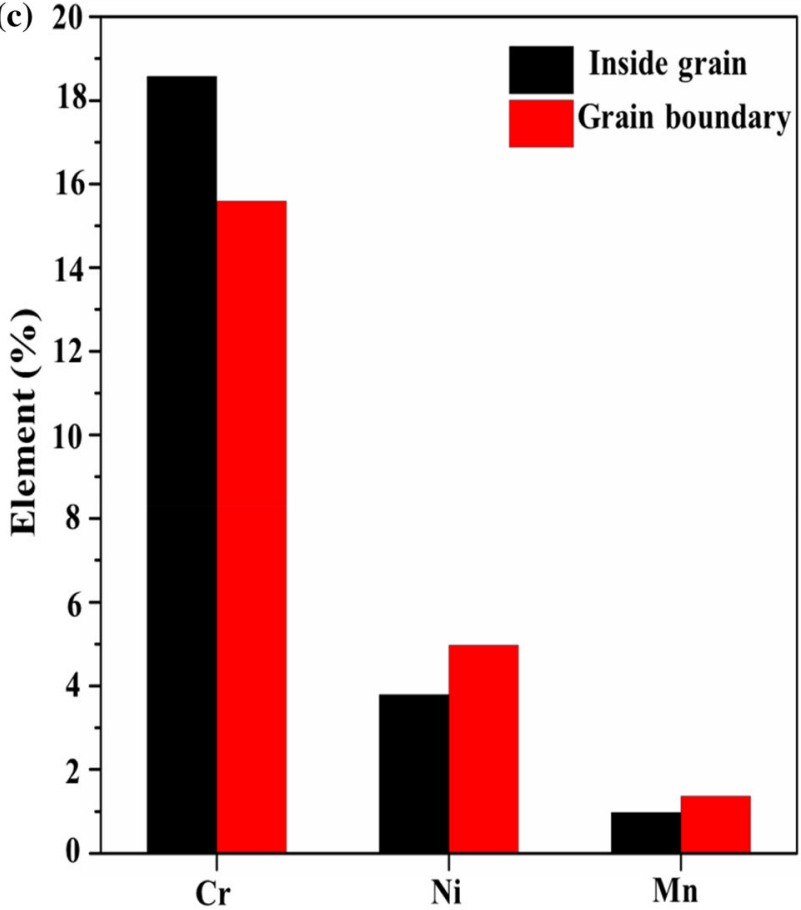

(d)

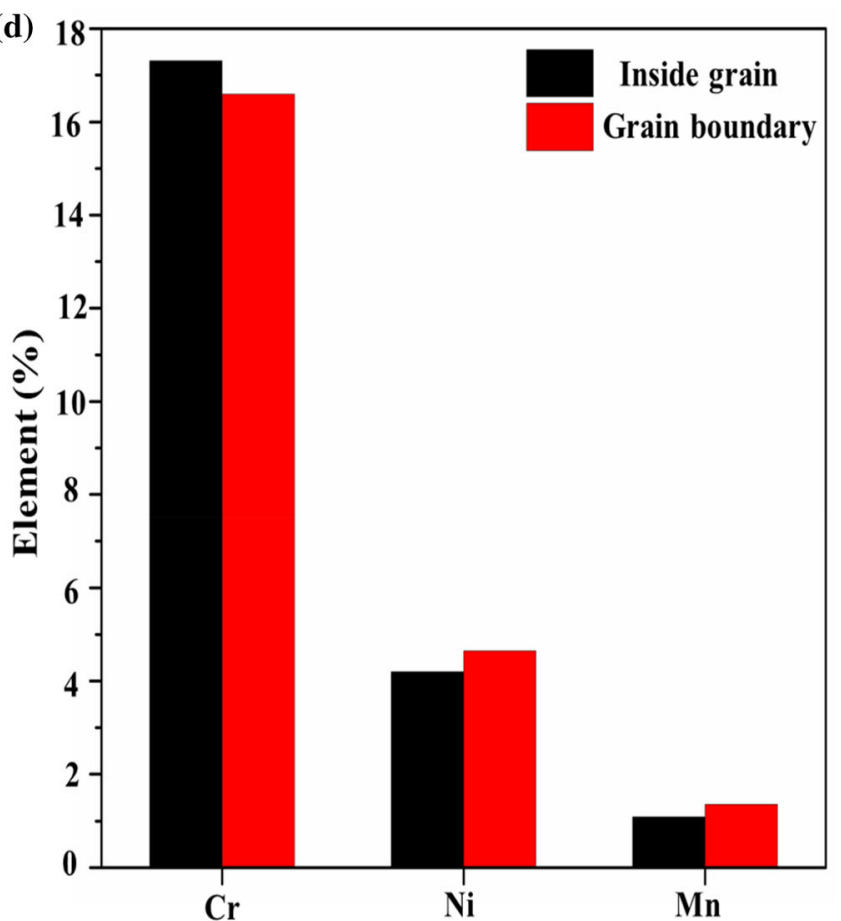

Fig. 4 EDX analysis and of WZ of (a) LHI, and (b) HHI weldments and their element variation estimated from EDX analysis in the WZ of (c) LHI and (d) HHI 

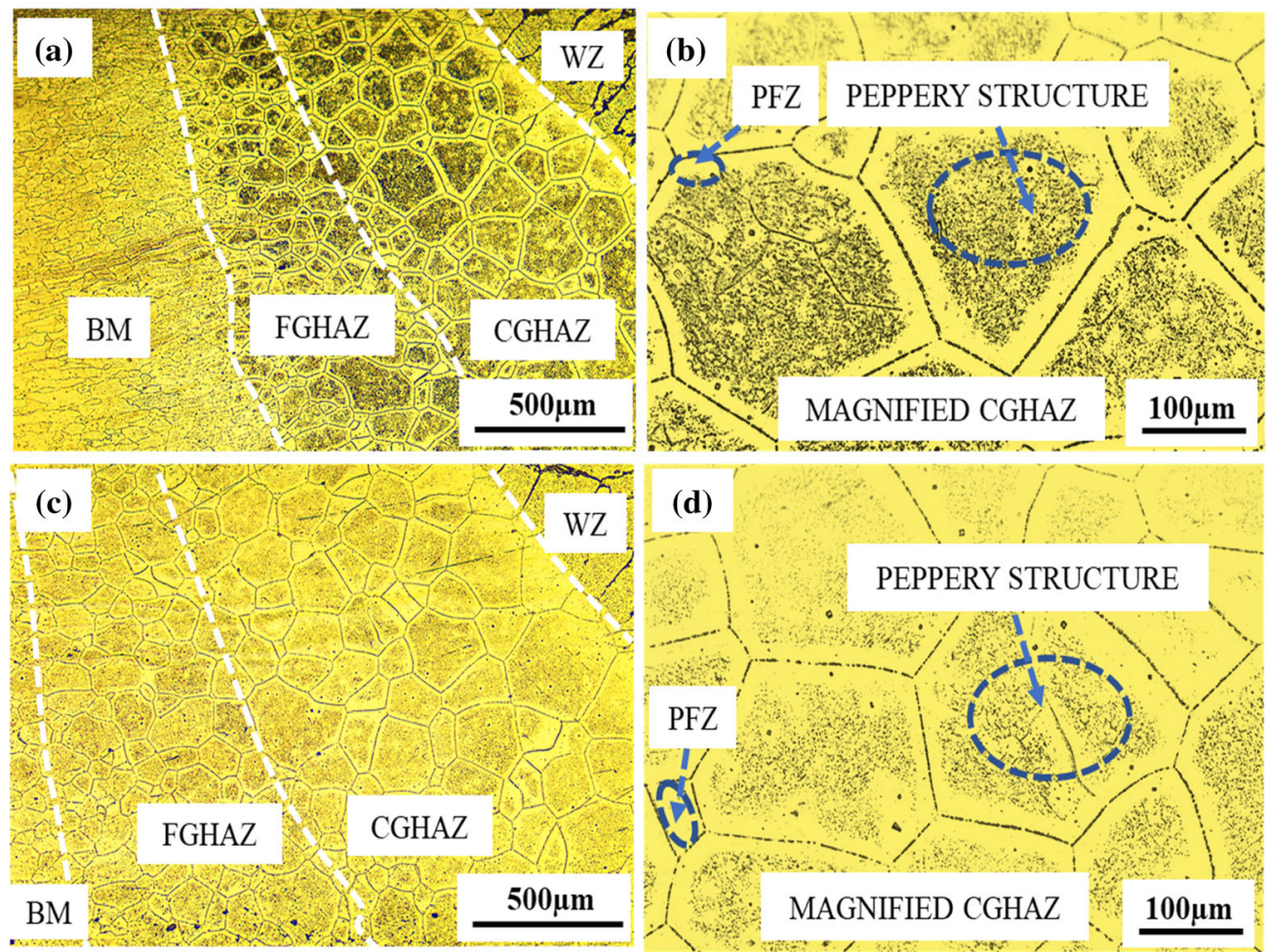

(d)
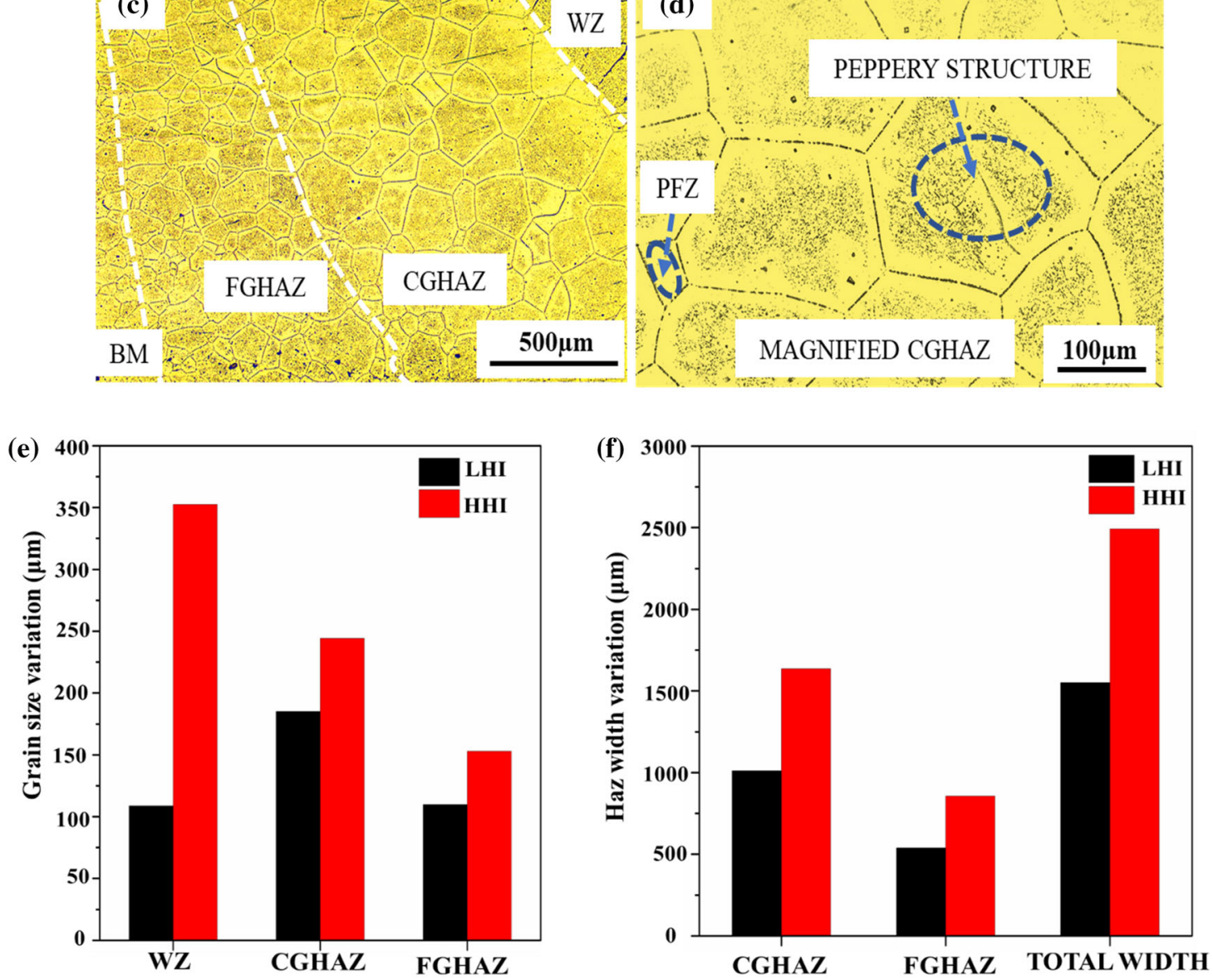

Fig. 5 Optical microstructures of HAZ (a-b) LHI and (c-d) HHI (e) grain size variation in WZ and HAZ (f) HAZ width variation of LHI and HHI weldments

The SEM-EDX analysis of the carbide precipitates in the HAZ of weldments is shown in Fig. 6(a-b). The variation in the chemical composition of different elements in the grain area and grain boundary regime is shown in Fig. 6(c, d). It can be observed from Fig. 6(c,d) that the peppery structure are $\mathrm{Cr}$ rich carbides as the higher content of $\mathrm{Cr}$ and $\mathrm{C}$ can be observed in the peppery structure than the ferrite grain boundaries. Also, it can be observed that the $\mathrm{Cr}$-rich carbide precipitation is higher in the HAZ of LHI weldment and its concentration decreases with an increase in heat input. Khorrami et al. (Ref 5) reported that the number of grain boundaries is majorly responsible for the short distance diffusion and formation of $\mathrm{Cr}$-rich precipitates. Figure 5(e) shows that the grain size of HAZ of LHI weldment is significantly smaller than the HHI weldment, and the smaller grain size resulted in the formation of a higher number of grain boundaries. These grain boundaries are mainly responsible for more short-distance diffusion of $\mathrm{C}$, which caused the formation of more amount of precipitates. Hence, it can be stated that the heat input plays an important role in the formation of a higher concentration of $\mathrm{Cr}$-rich precipitate inside the ferrite grain boundaries of HAZ of LHI weldment. Moreover, no precipitation is observed in the ferrite grain boundary of HAZ for both the weldments. 

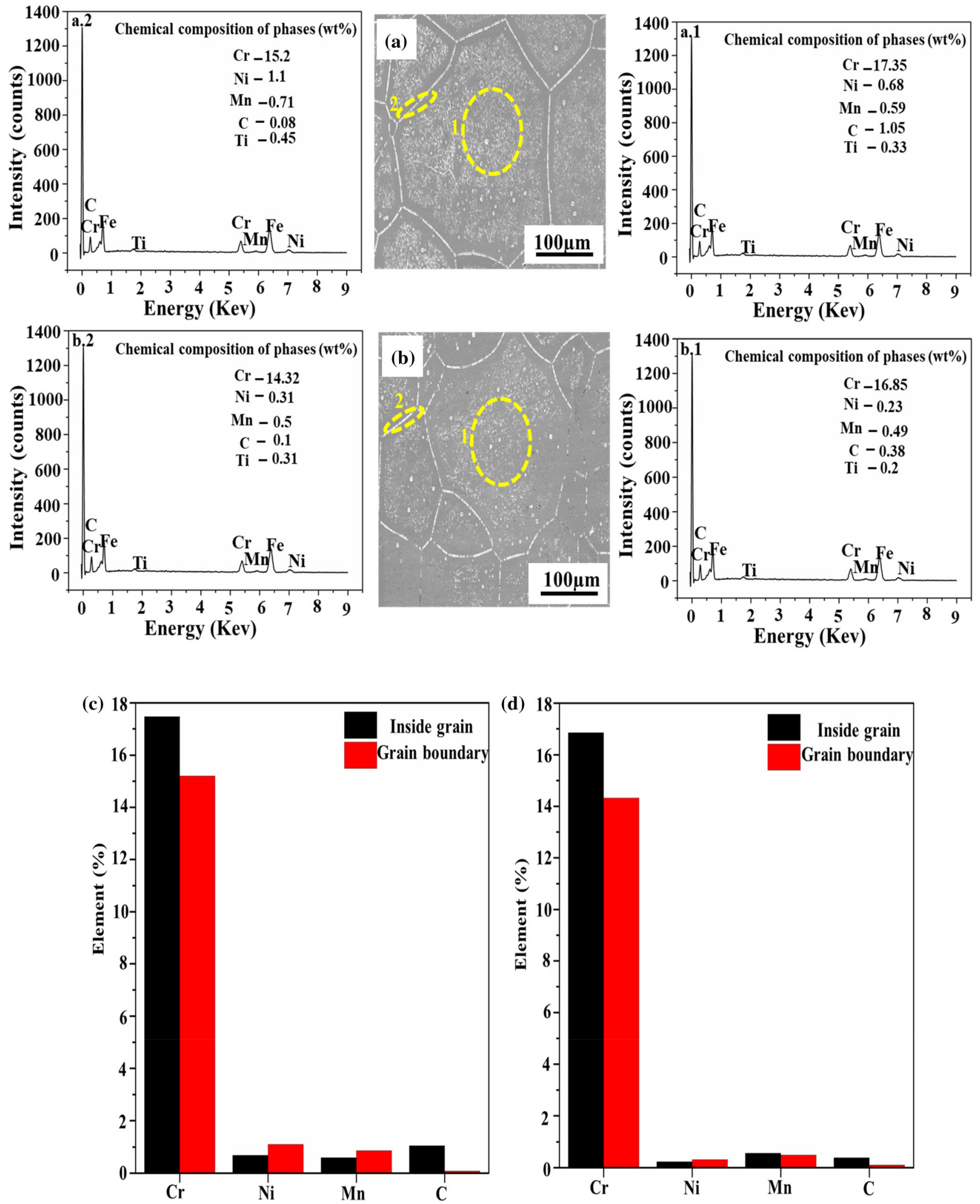

Fig. 6 EDX analysis and of HAZ of (a) LHI, and (b) HHI weldments and their element variation estimated from EDX analysis in the HAZ of (c) LHI and (d) HHI 

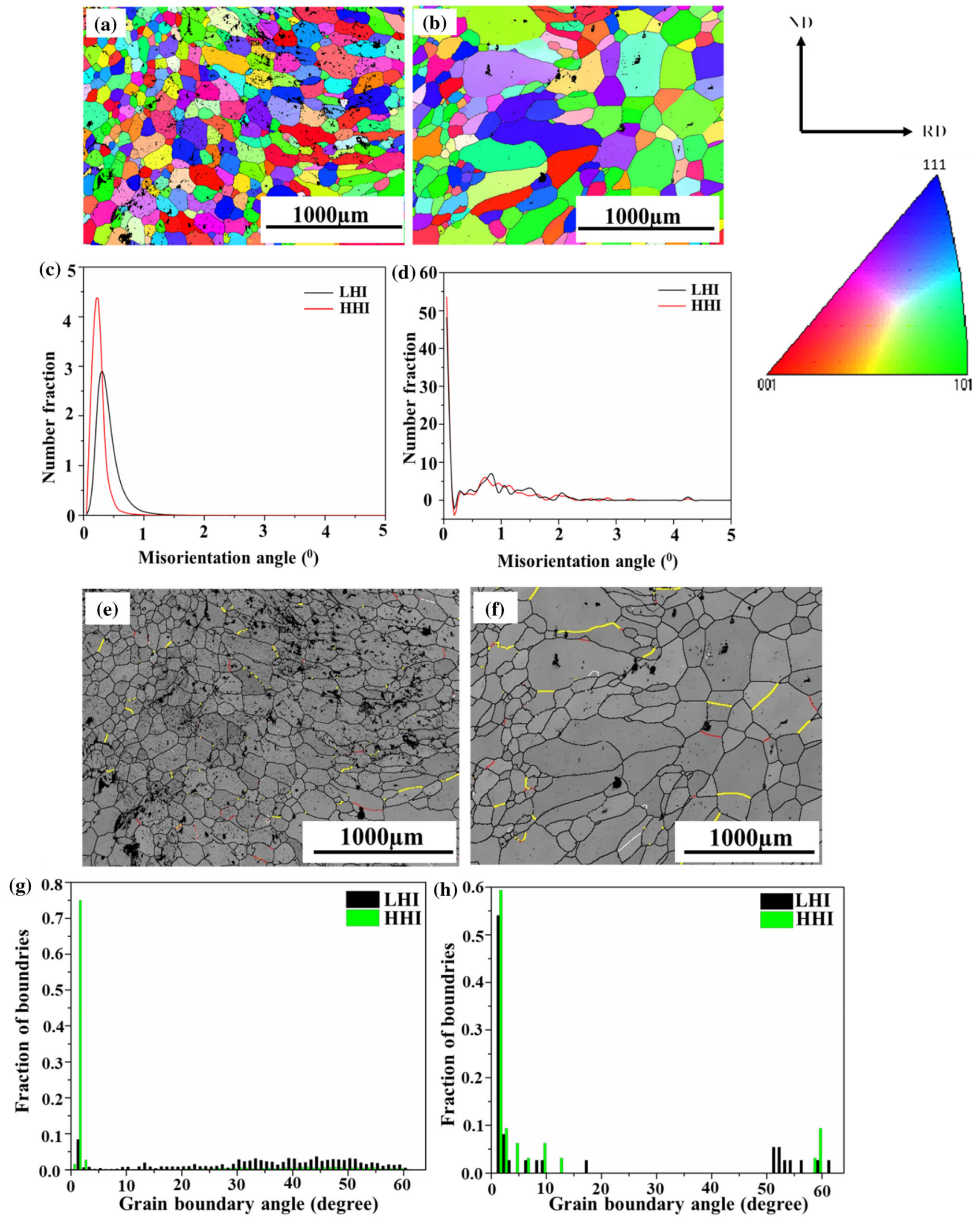

Fig. 7 Inverse pole figure of (a) LHI weldment, (b) HHI weldment (c) misorientation distribution (BCC-ferrite), and (d) misorientation distribution (FCC-RA). Grain boundary distribution in (e) LHI weldment (f) HHI weldment. Variation in fraction of grain boundary distribution in LHI and HHI weldments (g) BBC-ferrite (h) FCC-RA 

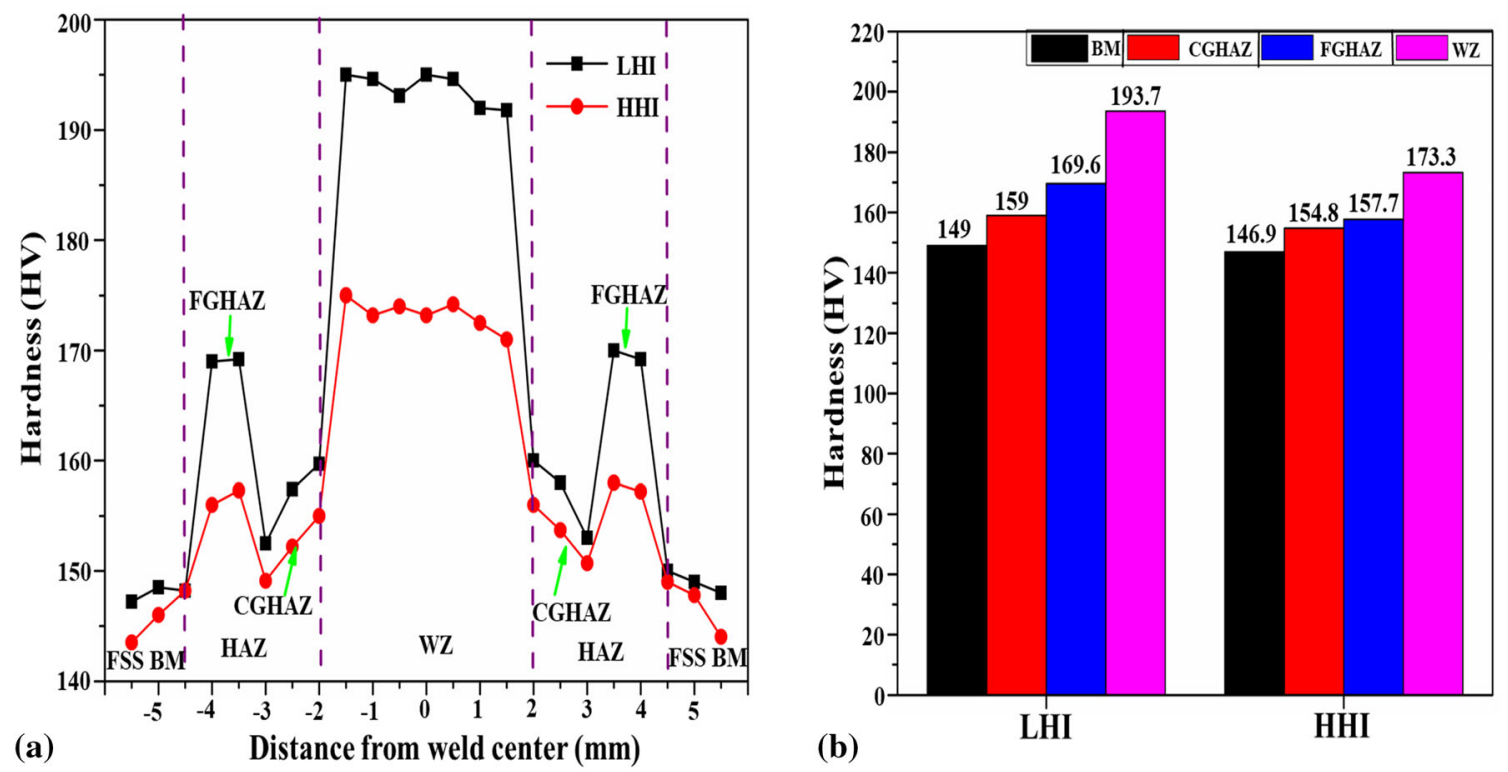

Fig. 8 (a) Micro-hardness profile (b) variation in micro-hardness values of the different heat input weldments

3.1.2 Electron Backscattered Diffraction Analysis. The EBSD analysis was used to study the micro-texture (orientation of crystallographic plane) of the weldments. The area from the WZ to HAZ of the weldments was scanned for analysis, and the inverse pole figure (IPF) map in the $\mathrm{Z}$ direction is shown in Fig 7. In Fig. 7(a), the IPF of LHI WZ shows the finer ferrite grains, whereas HHI WZ illustrates a coarser structure, as shown in Fig. 7(b). This is attributed to the increased heat input and slower cooling rate. The average local misorientation (LAM) method was used to quantify the strain generated during the thermal weld cycle and is shown in Fig. 7(c, d). Figure 7(c) shows the graph of LAM distribution for BCC structure (ferrite), and Fig. 7(d) shows the LAM distribution for FCC structure RA for both the weldments. The misorientation distribution of ferrite and RA phase is shown in Fig. 7(c, d). Figure 7(c) shows that the BCC structure in the LHI weldment shows a broader region than the HHI weldment. Moreover, it can be noticed that the peak of the BCC structure in the LHI weldment is shifted slightly toward the right side (Ref 31$)$. This can be attributed to the higher accumulation of strain generated in the LHI weldment during the solidification due to the presence of a higher volumetric fraction of RA. The peaks of FCC structure (Fig. 7d) in both the weldments showed no appreciable difference. This may be due to the lower concentration of FCC structure in the weldment as compared to the BCC structure.

Figure 7(e-h) shows the variation in different types of grain boundary for both the weldments, which consists of low angle grain boundary (LAGB, $\theta<5^{0}$ ), mean angle grain boundary $\left(5^{0}-15^{\circ}\right)$, and high angle grain boundary (HAGB, $\left.\theta>15^{\circ}\right)$ (Ref $32)$. Figure $7(e-f)$ depicts the grain boundary distribution for LHI and HHI weldments, and Fig. 7(g-h) illustrates the variation in grain boundary fraction for BCC (ferrite) and FCC (RA) structure. The fraction of grain boundary variation depends on welding parameters, and the fraction of LAGB is opposite to the fraction of HAGB. Saha et al. (Ref 33) stated that the higher fraction of HAGB restricts the motion of dislocation across the grain boundary area and the dislocation pile-ups restrict the grain growth during solidification. In contrast, low fraction HAGB is not capable of restricting the dislocation piles-ups. Figure $7(\mathrm{~g}, \mathrm{~h})$ shows that a higher fraction of HAGB is observed for LHI weldment as compared to its counterpart. Therefore, in the present study, a lesser grain size is observed in the WZ and HAZ of the LHI as compared to its counterpart (Fig. 5e).

\subsection{Mechanical Properties}

3.2.1 Micro-Hardness Analysis. The micro-hardness varies with heat input and the variation is greatly affected by the formation of different phases during solidification as shown in Fig. 8(a) and the variation in average micro-hardness values of various regions is shown in Fig. 8(b). The higher microhardness values of LHI weldment as compared to $\mathrm{HHI}$ weldment is ascribed to the formation of a higher amount of volumetric fraction of RA in the WZ of LHI weldment. The formation of RA at grain boundary restricts the grain growth, and consequently resulting in a higher number of grains and grain boundaries, which act as a barrier for the movement of dislocation. Therefore, the presence of higher volumetric fraction of RA and lesser grain size (Fig. 5(e)) in the WZ of LHI weldment resulted in higher micro-hardness values as compared to HHI weldment. Furthermore, it can be noticed that the average micro-hardness values of WZ decreased by 10.53 $\%$ for the HHI weldment. A similar trend is also observed in the HAZ of the weldments. The formation of intragranular precipitate in HAZ resulted in a decrease in $4.89 \%$ average micro-hardness values for the HHI weldment. In HAZ, variation in micro-hardness values in CGHAZ and FGHAZ can be ascribed to the variation in grain size (Fig. 5e).

The formation of a higher fraction of HAGB restricts the dislocation motion across the grain boundary (Ref 34 ), and it is observed that the higher fraction of HAGB is observed across the WZ to HAZ for the LHI weldment (Fig. 7(e, h)). Therefore, the micro-hardness values are higher for LHI as compared to its counterpart across the WZ to HAZ. Hence, the results are in consistent with the result obtained from the grain boundary EBSD analysis. 
(a)
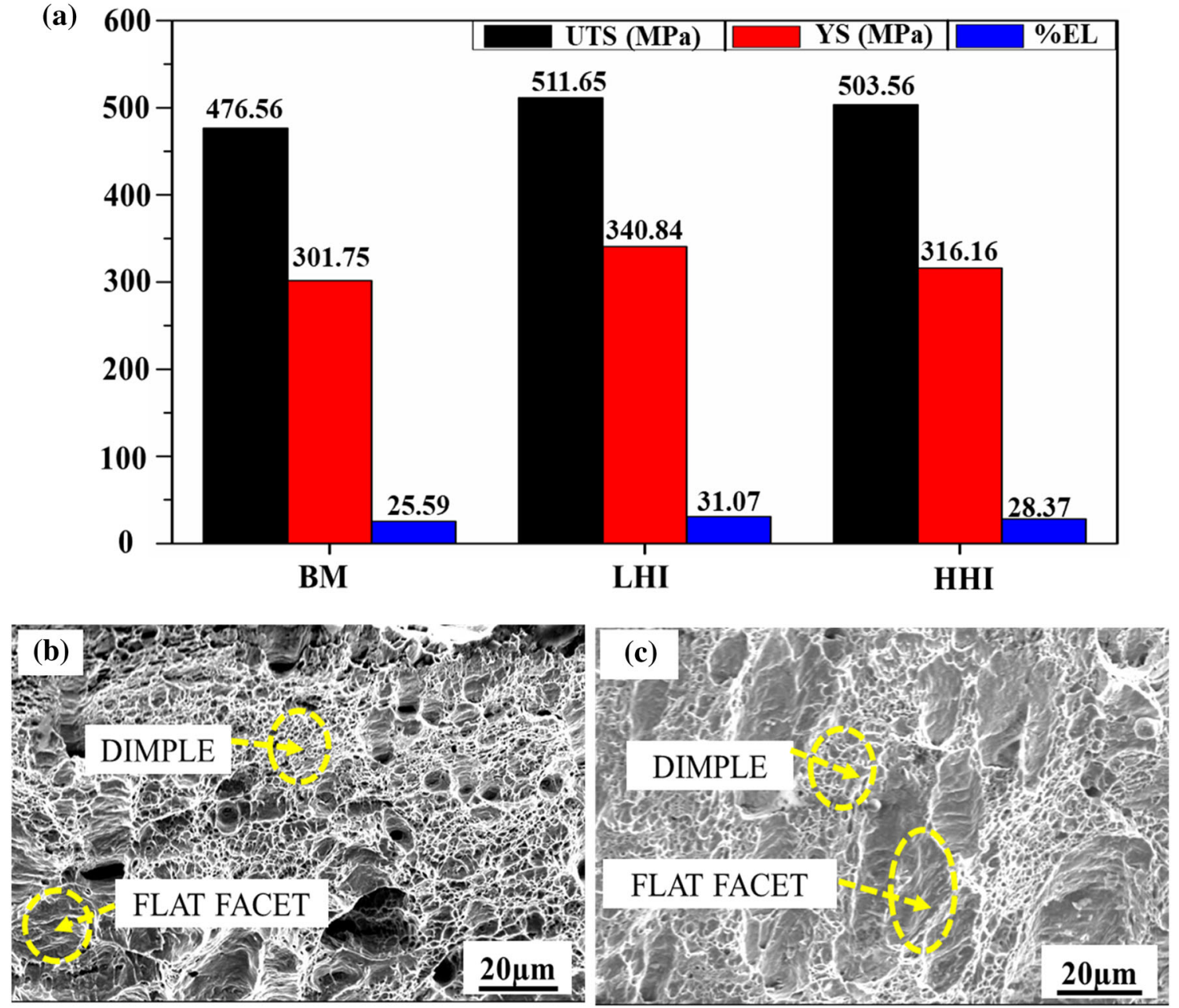

Fig. 9 (a) Tensile properties UTS - ultimate tensile strength, YS — yield strength, \% EL—\% elongation (b) fractography of LHI weldment (c) fractography of HHI weldment

3.2.2 Tensile Test Analysis. The tensile test results are shown in Fig. 9(a). Figure 9(a) shows that the LHI weldment illustrates $1.60 \%$ higher ultimate strength, $7.80 \%$ higher yield strength, and better ductility as compared to the HHI weld joint. The location of fracture is BM for both the weldments, which clearly shows that the strength of WZ is higher than the BM. As compared to single ferritic phase BM, the strength of $\mathrm{WZ}$ was significantly improved due to the formation of mixed microstructure (ferrite and RA) in the WZ (Fig. 3a, b) (Ref 26). From Fig. 5(a-d), it is observed that carbide precipitates are distributed over a wide area within the grains of HAZ for both weld joints, which significantly contributed to strengthening the HAZ (Ref 26). Hence, it can be stated that the strength of all the weldments is significantly enhanced by the presence of different phases in the WZ and by the presence of carbides in HAZ.

The fractographs of different weldments are shown in Fig. 9(b, c). From the micrographs, dimples with planar facets can be observed in both the weldments, indicating the fracture occurred in ductile as well as in brittle mode. The tensile properties of the weldment (shown in Fig. 9(a)) show that the ductility and strength decreased with an increase in heat input, resulting in more planar facets in $\mathrm{HHI}$ weldments.
Table 3 DLEPR result of test samples

\begin{tabular}{lccc}
\hline Sample & $\mathbf{I a}, \mathbf{1 0}^{\mathbf{- 3}}, \mathbf{A} / \mathbf{c m}^{\mathbf{2}}$ & $\mathbf{I r}, \mathbf{1 0}^{\mathbf{- 3}}, \mathbf{A} / \mathbf{c m}^{\mathbf{2}}$ & DOS, $\mathbf{I r} / \mathbf{I a * 1 0 0}$ \\
\hline BM & 103.15 & 4.31 & 4.17 \\
LHI & 2.25 & 0.36 & 16 \\
HHI & 4.61 & 0.25 & 5.42 \\
\hline
\end{tabular}

\subsection{Corrosion Behavior-Double-Loop Potentiokinetic Reactivation (DLEPR) Test Analysis}

The DLEPR test was performed to evaluate the susceptibility of different welded samples toward IGC. The formation of chromium-rich carbides or any other precipitates influences the depletion of chromium in nearby regions during welding of stainless steels. This depletion of chromium generates the potential difference between grain and grain boundary, accelerating the grain boundary attack, which further depends on the availability of anodic sites near the grain boundary (Ref 21). In the DLEPR test, two scans were performed, i.e., forward and reverse scan. In forward scan, the whole surface of the test sample gets passivated, and the maximum current density sample takes for passivation is taken as $\mathrm{I}_{\mathrm{a}}$. In reverse scan, depassivation starts, and passive layer breaks in the anodic sites 

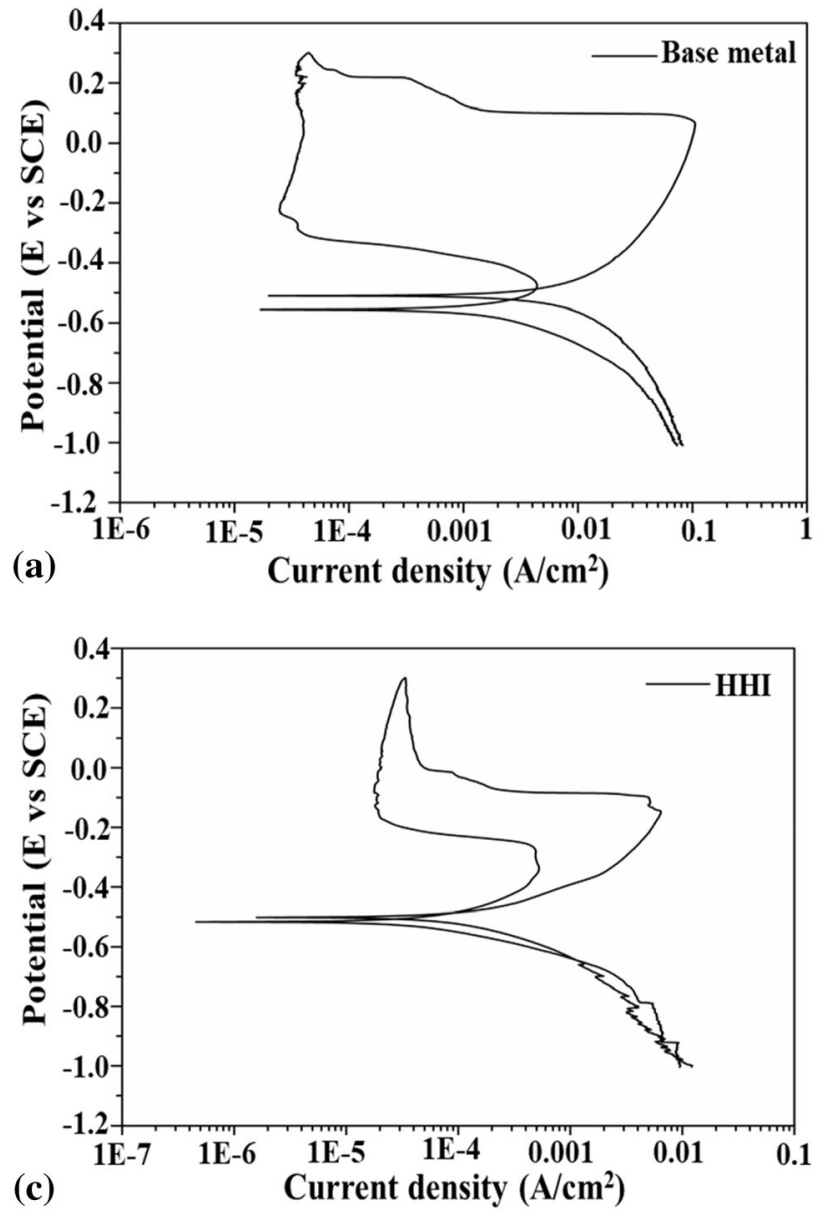

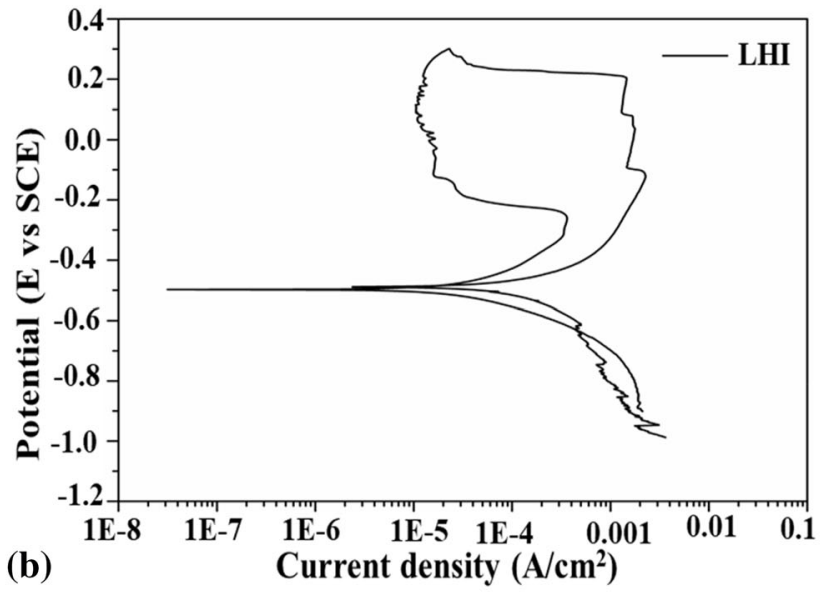

(d)

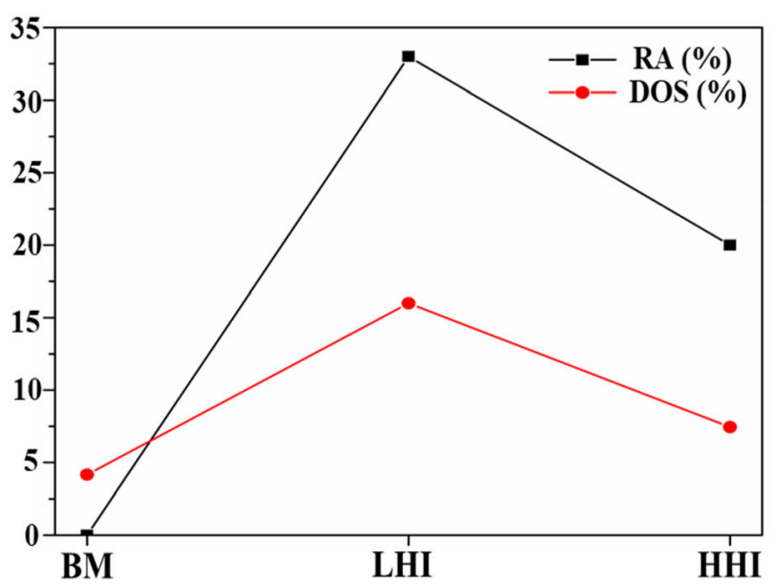

Fig. 10 DLEPR curves of (a) BM (b) LHI (c) HHI and (d) Variation of RA (\%) and DOS (\%) of base metal and weldments

or chromium-depleted areas because passive film dissolves very easily in these areas with decreasing potential, and the maximum current density during depassivation is taken as $\mathrm{I}_{\mathrm{r}}$. Then, the value of these two peak current densities gives the quantitative data about degree of sensitization (DOS), and it was calculated by the ratio of ( $\left.\operatorname{Ir} / \mathrm{Ia}^{*} 100\right)$ ( $\left.\operatorname{Ref} 34\right)$.

The DLEPR test results are shown in Table 3. The DLEPR curves of WZ for LHI and HHI weld joints, and BM are shown in Fig. 10(a-c), and the DOS and its correlation with the volumetric fraction of RA are shown in Fig. 10(d). The BM shows the lower DOS due to single-phase ferrite microstructure and no carbides and/or precipitates were found in optical microstructure or XRD peaks (Fig. (2)). In WZ of different heat inputs, DOS is higher of both the weldments as compared to the $\mathrm{BM}$ attributed to the formation of mixed microstructure. The presence of RA at the grain boundary resulted in the depletion of chromium at the grain boundary (as can be observed by the EDS analysis (Fig. 4) of both the weldments). The WZ of LHI weldment has a higher volumetric fraction of RA, resulting in higher number grain boundaries, consequently higher sensitization sites. Hence, it can be stated that the DOS is proportional to the volumetric fraction RA, and therefore, a higher DOS is observed in LHI weldment as compared to the HHI weldment. With the increase in heat input, the DOS deceased from $16 \%$ for the WZ of LHI weldment to $5.42 \%$ for the WZ of HHI weldment.

\section{Conclusions}

1. In the present work, GTAW technique was employed for welding of 439 Ti-stabilized FSS using 308L filler material with varying heat input.

2. The microstructural evolution for both the weldments consists of mixed microstructure (ferrite + RA) and variation in grain size with varying heat input. The RA formed at ferrite grain boundary and the volumetric fraction of RA decreased with increase in heat input, and the estimated volumetric fraction of RA calculated using XRD analysis is $33.33 \%$ and $20.42 \%$ in the WZ of LHI and HHI weldments, respectively.

3. The HAZ area can be divided into CGHAZ and FGHAZ attributed to the variation in temperature gradient, and width of HAZ is higher for HHI weldment. The peppery structure was in HAZ of both the weldments; however, the concentration was higher in LHI HAZ.

4. The local misorientation distribution is higher for LHI weldment than HHI weldment attributed to the higher volumetric fraction of RA.

5. The micro-hardness results depicted the higher microhardness values for LHI weldment and is ascribed to the presence of higher volumetric fraction of RA at grain boundary which restricts the grain growth and act as a barrier for dislocation movements. 
6. The WZ of LHI weldment showed higher \% DOS due to the higher volumetric fraction of RA at ferrite grain boundary which is responsible for more $\mathrm{Cr}$ depletion near the grain boundary.

\section{Funding}

Open access funding provided by Manipal Academy of Higher Education, Manipal.

\section{Open Access}

This article is licensed under a Creative Commons Attribution 4.0 International License, which permits use, sharing, adaptation, distribution and reproduction in any medium or format, as long as you give appropriate credit to the original author(s) and the source, provide a link to the Creative Commons licence, and indicate if changes were made. The images or other third party material in this article are included in the article's Creative Commons licence, unless indicated otherwise in a credit line to the material. If material is not included in the article's Creative Commons licence and your intended use is not permitted by statutory regulation or exceeds the permitted use, you will need to obtain permission directly from the copyright holder. To view a copy of this licence, visit http://creativecommons.org/licenses/by/4.0/.

\section{References}

1. M.O.H. Amuda and S. Mridha, Grain Refinement and Hardness Distribution in Cryogenically Cooled Ferritic Stainless Steel, Mater. Des., 2013, 47, p 365-371

2. N. Ghosh, P.K. Pal and G. Nandi, GMAW Dissimilar Welding of AISI 409 Ferritic Stainless Steel to AISI 316L Austenitic Stainless Steel by Using AISI 308 Filler Wire, Eng. Sci. Technol. Int. J., 2017, 20, p 1334-1341

3. M. Gurram, K. Adepu, R.R. Pinninti and M.R. Gankidi, Effect of Copper and Aluminium Addition on Mechanical Properties and Corrosion Behaviour of AISI 430 Ferritic Stainless Steel Gas Tungsten Arc Welds, J. Mater. Res. Techn., 2012, 2, p 238-249

4. G.M. Reddy, T. Mohandas, A.S. Rao and Y.V. Satyanarayana, Influence of Welding Processes on Microstructure and Mechanical Properties of Dissimilar Austenitic-Ferritic Stainless Steel Welds, Mater. Manuf. Processes., 2005, 20, p 147-173

5. M. Sarkari Khorrami, M. A. Mostafaei, H. Pouraliakbar and A. H. Kokabi, A Study on Microstructure and Mechanical Characteristics of Low-Carbon Steel and Ferritic Stainless Steel Joints. Mater. Sci. Eng. A., 2014, 608, p 35-45

6. M.A. Khattak, S. Zaman, M. Tamin, S. Badshah, S. Mushtaq and A.A.B. Omran, Effect of Welding Phenomenon on the Microstructure and Mechanical Properties of Ferritic Stainless Steel-a Review, Akademia Baru, 2017, 32, p 13-31

7. L. Tanure, C.M. De Alcântara, D.B. Santos, T.R. De Oliveira, B.M Gonzalez and K. Verbeken, Microstructural Characterization and Mechanical Behaviour During Recrystallization Annealing of NbStabilized Type ASTM 430 and Nb-Ti-Stabilized ASTM 439 Ferritic Stainless Steels, J. Mater. Technol., 2019, 8, p 4048-4065

8. T. Mohandas, G. Madhusudhan Reddy and M. Naveed, Comparative Evaluation of Gas Tungsten and Shielded Metal Arc Welds of a 'ferritic' Stainless Steel, J. Mater. Processing Tech., 1999, 94, p 133140

9. C.C. Silva, J.P. Farias, H.C. Miranda, R.F. Guimarães, J.W.A. Menezes and M.A.M. Neto, Microstructural Characterization of the HAZ in AISI 444 Ferritic Stainless Steel Welds, Mater. charact., 2008, 59, p $528-533$
10. M. Alizadeh-Sh, S.P.H. Marashi and M. Pouranvari, Resistance Spot Welding of AISI 430 Ferritic Stainless Steel: Phase Transformations and Mechanical Properties, J. Mater. Des., 2014, 56, p 258-263

11. A.K. Lakshminarayanan, K. Shanmugam and V. Balasubramanian, Effect of Welding Processes on Tensile and Impact Properties, Hardness and Microstructure of AISI 409M Ferritic Stainless Joints Fabricated by Duplex Stainless Steel Filler Metal, J. Iron Steel Res. Int., 2009, 16, p 66-72

12. J.K. Kim, Y.H. Kim, S.H. Uhm, J.S. Lee and K.Y. Kim, Intergranular Corrosion of Ti-Stabilized $11 \mathrm{wt} \% \mathrm{Cr}$ Ferritic Stainless Steel for Automotive Exhaust Systems, Corrs. Sci., 2009, 51, p 2716-2723

13. A.K. Lakshminarayanan and V. Balasubramanian, Use of DL-EPR Test to Assess Sensitization Resistance of AISI 409M Grade Ferritic Stainless Steel Joints, J. Mater. Eng. Perform., 2013, 22, p 2293-2303

14. M. Mukherjee and T.K. Pal, Influence of Heat Input on Martensite Formation and Impact Property of ferritic-Austenitic Dissimilar Weld Metals, J. Mater. Sci. Technol., 2012, 28, p 343-352

15. M. Shojaati and B. Beidokhti, Characterization of AISI 304 / AISI 409 Stainless Steel Joints Using Different Filler Materials, Const. Building Mater., 2007, 147, p 608-615

16. W. Lippold J C and Kotecki DJ, Welding Metallurgy and Weldability of Stainless Steel. A john wiley and Sons, 2005

17. J. M. Salgado López, M. Preud Homme, F. Lopez Monroy, J. L. Ojeda Elizarráraz and A. Toscano Giles, Microstructure and Mechanical Properties of AISI 439 Ferritic Stainless Steel Welds without Filler Metal, Acta Universitaria., 2019, 29, p 1-12

18. L. D. A. Silva, L. Iglesias, L. Lima and W. Reis, Microstructural Characterization of HAZ of the AISI 439 with Different heat Input, Int. Nucl. Atlantic Confer., 2007, p 1-6

19. J. Verma, R.V. Taiwade, R. Kataria and A. Kumar, Welding and Electrochemical Behavior of Ferritic AISI 430 and Austeno-Ferritic UNS 32205 Dissimilar Welds, J. manuf. Process., 2018, 34, p 292-302

20. H. Vashishtha, R.V. Taiwade, S. Sharma and A.P. Patil, Effect of Welding Processes on Microstructural and Mechanical Properties of Dissimilar Weldments Between Conventional Austenitic and High Nitrogen Austenitic Stainless Steels, J. Manuf. Processes., 2017, 25, p 49-59

21. J. Verma, R.V. Taiwade, R.K. Khatirkar, S.G. Sapate and A.D. Gaikwad, Microstructure, Mechanical and Intergranular Corrosion Behavior of Dissimilar DSS 2205 and ASS 316L Shielded Metal Arc Welds, Trans. Indian Inst. Met., 2017, 70, p 225-237

22. R.H. Kaltenhauser, Improving the Engineering Properties of Ferritic Stainless Steels, Met. Eng. Quarterly., 1971, 11, p 41-47

23. S. K. Gupta, A. R. Raja, M. Vashista and M. Z. K. Yusufzai, Effect of Heat Input on Microstructure and Mechanical Properties in Gas Metal Arc Welding of Ferritic Stainless Steel, Maters. Res. Exp., 2019, 6

24. H. Vashishtha, R.V. Taiwade, R.K. Khatirkar and A.S. Dhoble, Effect of Austenitic Fillers on Microstructural and Mechanical Properties of Ultra Low Nickel Austenitic Stainless Steel, Sci. Technol. Weld Join, 2016, 21, p 331-337

25. V. Tandon, A. P. Patil and R. C. Rathod, Correlation of Martensite Content and Dislocation Density of Cold Worked 316L on Defect Densities of Passivating Film in Acidic Environment, Mater. Res. Exp., 2018, 5

26. J. Zhou, J. Shen, S. Hu, G. Zhao and Q. Wang, Microstructure and Mechanical Properties of AISI 430 Ferritic Stainless Steel Joints Fabricated by Cold Metal Transfer Welding, Mater. Res. Exp., 2019, 6

27. X. Zhang, Y. Zhang, Y. Wu, S. Ao and Z. Luo, Effects of MeltingMixing Ratio on the Interfacial Microstructure and Tensile Properties of Austenitic-Ferritic Stainless Steel Joints, J. Mater. Res. Technol., 2019, 8, p 2649-2661

28. S. Balbande, R. V. Taiwade, A. P. Patil and U. Pathak, Cold Metal Transfer Welding of Duplex with Ferritic and Super Austenitic Stainless Steel, Mater. Res. Exp., 2019, 6

29. C. Köse and C. Topal, Effect of Post Weld Heat Treatment and Heat Input on the Microstructure and Mechanical Properties of Plasma Arc Welded AISI 410S Ferritic Stainless steel, Mater. Res. Exp., 20196

30. V. Tandon, M.A. Thombre, A.P. Patil, R.V. Taiwade and H. Vashishtha, Effect of Heat Input on the Microstructural, Mechanical, and Corrosion Properties of Dissimilar Weldment of Conventional Austenitic Stainless Steel and Low - Nickel Stainless Steel, Meta. Micro. Analysis., 2020, 9, p 668-677

31. T.R. Dandekar, A. Kumar, R.K. Khatirkar, D. Mahadule and G. Ayyappan, Multistep Cross Rolling of UNS S32101 Steel: Microstructure, Texture, and Magnetic Properties, J. Mater. Eng. Perform., 2021, 30, p 2916-2929 
32. H. Mostaan, M. Shmanian, R. Moradi, F. Nematzadeh, A. Sonboli and J.A. Szpunar, Weld zone Characterization of Dissimilar SS UNS S43000/UNS S32304 Joined Through Laser Beam Welding: EBSD Study, Phase Evolutions, and Fractography, J. Mater. Eng. Perform., 2020, 29, p 7744-7754

33. S. Saha, M. Mukherjee and T.K. Pal, Microstructure, Texture, and Mechanical Property Analysis of Gas Metal Arc Welded AISI 304 Austenitic Stainless Steel, J. Mater. Eng. Perform., 2015, 24, p 11251139
34. J. Verma and R.V. Taiwade, Dissimilar Welding Behavior of $22 \% \mathrm{Cr}$ Series Stainless Steel with $316 \mathrm{~L}$ and its Corrosion Resistance in Modified Aggressive Environment, J. Manuf. Processes., 2016, 24, p $1-10$

Publisher's Note Springer Nature remains neutral with regard to jurisdictional claims in published maps and institutional affiliations. 